\title{
Pediatric Aphakic Glaucoma
}

\author{
Zia Muhammad, John Grigg, Ikramullah, Ihsan Ali
}

Pak J Ophthalmol 2019, Vol. 35, No. 3

See end of article for authors affiliations

Correspondence to:

Zia Muhammad

Prof \& Head Department of Ophthalmology, Bacha Khan Medical College, Mardan, Pakistan.

Email: eyesurgzia@gmail.com
Purpose: To find the frequency and pathogenesis of post-operative aphakic glaucoma in children operated for congenital cataract at Mardan Medical Complex, Mardan, Pakistan.

Study Design: Retrospective Cohort study.

Place and Duration of Study: Mardan Medical Complex, Mardan between January 2001 and December 2014.

Material and Methods: All cases were operated for congenital cataracts between the ages of 2 months to 30 months were included in the study. Babies having congenital cataracts with increased intraocular pressure (IOP), those showing signs of congenital glaucoma and those having congenital cataracts with specific syndromes were not included in the study.

Results: We reviewed the records of 110 patients who had bilateral lens aspiration for congenital cataracts. We found 7 patients (12 eyes) who developed increased intra-ocular pressure (IOP) after bilateral lens matter aspiration for congenital cataracts. Four patients (three males one female), developed early onset pupil block glaucoma, (2 bilateral and 2 unilateral) while in 3 female patients the onset of glaucoma was delayed for several months to years and was of the open angle type in both the eyes. Poor compliance with follow up, poor pupillary dilatation, prolonged surgical time, severe inflammation and residual lens matter are some of the risk factors for early onset pupillary block aphakic glaucoma in pediatric age group.

Conclusions: Pediatric aphakic glaucoma is a significant complication of congenital cataract surgery which requires continuous followup of the patients.

Key Words: Pediatric aphakic glaucoma, Congenital cataract, Aphakic open angle glaucoma, Pupil block, Primary posterior capsulotomy,
A phakic Glaucoma is one of the most serious, sight threatening and well recognized complications following uncomplicated pediatric cataract surgery ${ }^{1,2}$. The incidence has been reported in the literature to be between $15 \%$ and $45 \% 3$. The incidence of aphakic glaucoma seems to increase when these patients are followed up for longer periods. 2,4 In patients who were watched for more than 5 years, the incidence of glaucoma in aphakic patients has reached to levels as high as $41 \% 4$.

Pupillary block glaucoma is becoming less common because of the technical innovations and improvements in ophthalmic equipments, cutting instruments and procedures. However, aphakic glaucoma still is a challenge and a sight threatening complication of pediatric cataract surgery $2,4,5$. Some of these children may develop aphakic glaucoma with open angles. The exact pathogenesis of this form of open angle glaucoma in these patients is unknown ${ }^{5}$.

The diagnosis of aphakic glaucoma in children with open angles is quite a challenging task and at times difficult to detect. Poor post-operative follow-up and absence of typical symptoms increases the risk of delayed diagnosis. Also patients need to be examined under general anesthesia to reach the diagnosis. Aphakic children require regular monitoring for IOP 
and optic disc changes.

Aphakic Glaucoma occurring after removal of congenital cataract is an established complication. Mills et $\mathrm{al}^{2}$ have observed a bimodal presentation of aphakic glaucoma in children. It may be in the form of pupillary block glaucoma due sticking of the pupillary margin to the anterior vitreous face; or due to angle closure from peripheral anterior synechiae ${ }^{2,3}$. Or it may be an open angle type glaucoma of late onset.

Surgery before 9 months of age and micro-cornea are two important risk factors for development of glaucoma following pediatric cataract surgery. It has been recognized that visual outcome is excellent if surgery is performed in neonates during the first few weeks of life ${ }^{6,7}$. But early surgery between 1-2 weeks of age also make the babies vulnerable to develop aphakic glaucoma ${ }^{8}$. Johnson et $\mathrm{al}^{9}$, have not observed any relationship between age at cataract surgery (prior to 12 weeks of age) and development of glaucoma. Others ${ }^{10}$ have reported a greater risk of glaucoma during the initial nine months of age.

We undertook this study to find out the frequency of aphakic glaucoma in the patients operated for congenital cataracts at our Institution. This will help us identify the causes of pediatric aphakic glaucoma. Also we may be able to modify our techniques to avoid this vision threatening complication.

\section{MATERIAL AND METHODS}

We analyzed the documents of all pediatric patients who were operated for congenital cataracts between the ages of two months to 30 months from January 2001 to December 2014. Babies having congenital cataracts with increased intraocular pressure (IOP), those showing signs of congenital glaucoma and those having congenital cataracts with specific syndromes were not included in the study.

Patients were labeled as having aphakic glaucoma if repeated intraocular pressure (IOP) measurements were greater than $25 \mathrm{~mm} \mathrm{Hg}$ after follow up of these patients. Schiotz and Perkins applanation tonometers were used to determine IOP.

In all our patients, we performed closed chamber anterior capsulotomy followed by lens matter aspiration through a limbal incision. No posterior capsulotomy and no vitrectomy was performed. All patients were left aphakic, and none of the patients received intraocular lens (IOL) implant. One hundred and ten lens aspirations were performed by the same surgeon (ZM). Both eyes were operated in the same sitting taking strict aseptic precautions. After completion of the surgical procedure, all patients received sub-conjunctival injections of Gentamycin and Dexamethasone. Topical medications (hourly dexamethasone (Maxidex, Alcon) and 4 hourly Tropicamide 1\% (Mydriacyl 1\%, Alcon) eye drops were started 2 hours after the operation. From the next day 2 hourly dexamethasone and 4 hourly Tropicamide $1 \%$ were continued over a 6 week period. Moxifloxicin eye ointment at night was used for couple of weeks. We re-examined the patients on the $3^{\text {rd }}$ day post-operative day to assess the wound, pupil, performed retinoscopy and advised glasses.

\section{RESULTS}

We reviewed the records of 110 patients who had bilateral lens aspiration for congenital cataracts. We found 7 patients (12 eyes) developed increased intraocular pressure (IOP) after bilateral lens matter aspiration for congenital cataracts. Four patients (three males one female), developed early onset pupil block glaucoma, (2 bilateral and 2 unilateral) while in 3 female patients the onset of glaucoma was delayed for several months to years and was of the open angle type in both the eyes. Descriptive analysis of the study is given in tables 1-5.

Table 1: Demography.

Total No. of Patients:

110

No. of Male Patients:

$69(62.73 \%)$

No. of Female patients:

$41(37.27 \%)$

Table 2: Age \& Sex Distribution.

\begin{tabular}{|cccc|}
\hline Age & Males & Females & Total \\
\hline 2 - 6 Months & 30 & 16 & $46(41.81 \%)$ \\
7 - 12 Months & 21 & 15 & $36(32.72 \%)$ \\
$13-30$ Months & 18 & 10 & $28(25.45 \%)$ \\
\hline
\end{tabular}

Table 3: No. of Patients who developed Aphakic Glaucoma 07 (6.36\%).

\begin{tabular}{|lccc|}
\hline Age & Males & Females & Total \\
\hline $1-6$ Months & 02 & 01 & 03 \\
$7-12$ Months & 01 & 02 & 03 \\
$13-30$ Months & Nil & 01 & 01 \\
\hline
\end{tabular}


Table 4: Type of Glaucomas.

\begin{tabular}{|lccl|}
\hline Age & $\begin{array}{c}\text { Pupil Block } \\
\text { glau. }\end{array}$ & $\begin{array}{c}\text { Open Angle } \\
\text { Glau. }\end{array}$ & Total \\
\hline 2-6 Months & 03 & & M 02/F 01 \\
7 -12 Months & 01 & 01 & M 0/F02 \\
13-30 Months & & 02 & M 0/F 02 \\
\hline
\end{tabular}

Table 5: Details of Patients Who Developed Aphakic Glaucoma.

\begin{tabular}{|llllcll|}
\hline No. & Name/Age/Sex & LMA Date & A G Dx. On & $\begin{array}{c}\text { Surgery } \\
\text { for AG }\end{array}$ & Type of AG & Gap \\
\hline 1. & Patient A 4 months/M & March 2012 & May 2012 & $10 / 5 / 2012$ & Right eye Pupil block & 67 days \\
2. & Patient B 5 months/M & May 2014 & June 2014 & $10 / 6 / 2014$ & Left eye Pupil block & 19 days \\
3. & Patient C 5 months/F & March 2008 & April 2008 & $22 / 4 / 2008$ & Bilateral Pupil block & 28 days \\
4. & Patient D 8 months/M & February 2013 & March 2013 & $12 / 3 / 2013$ & Bilateral Pupil block & 33 days \\
5. & Patient E 12 months/F & February 2004 & May 2004 & $6 / 5 / 2004$ & Bilateral OA glaucoma & 78 days \\
6. & Patient G 18 months/F & August 20013 & February 2014 & $25 / 2 / 2014$ & Bilateral OA glaucoma & 6 months \\
7. & Patient H 30 months/F & June 2005 & June 2011 & $16 / 6 / 2011$ & Bilateral OA glaucoma & 6 years \\
\hline
\end{tabular}

\section{DISCUSSION}

Congenital cataracts may be classified as congenital idiopathic cataracts, congenital cataracts associated with other ocular or systemic anomalies (aniridea, congenital rubella syndrome etc) and Developmental cataracts ${ }^{10}$.

The angle findings are normal in congenital idiopathic cataracts and signs of glaucoma and increased IOP are usually not present. ${ }^{11}$ Glaucoma in these children results from the surgical removal of cataracts with or without IOL implantation.

The diagnostic criteria as defined by the Glaucoma Research Network consist of two or more of the following: IOP more than $21 \mathrm{~mm} \mathrm{Hg}$, progressive increase in the cup to disc (C/D) ratio, asymmetrical cupping of the discs, corneal Haab's striae, enlarged corneal diameter $(>11 \mathrm{~mm}$ in the newborn, $>$ than 12 $\mathrm{mm}$ in children below one year and $>$ than $13 \mathrm{~mm}$ at any age and progressive myopia/myopic shift. Glaucoma may be suspected when there is increase in the size of the globe with raised IOP without other features mentioned above.

We reviewed all infants 3 weeks post surgery and enquired from the mother about the progress and development of any new symptoms. The common symptoms in suspected cases were photophobia and irritability of the infants. Infants with these symptoms were called for examination under general anesthesia for IOP measurement, assessment of anterior chamber angle and depth, horizontal corneal diameters, refraction and fundus examination. Aphakic glaucoma was suspected when the baby was having repeated intraocular pressures (IOPs) greater than $25 \mathrm{~mm} \mathrm{Hg}$, progressive increase in the $\mathrm{C} / \mathrm{D}$ ratio and increase in the horizontal corneal diameter after congenital cataract surgery. Schiotz or Perkins applanation tonometry was used to determine intra-ocular pressures. Patients with these findings were started with medical treatment or glaucoma surgery if the pressure was not controlled with topical medications. Glaucomatous eyes with pupil block and shallow anterior chambers were treated with removal of the inflammatory pupillary membrane if present, breaking the posterior synechie, peripheral iridectomy and anterior vitrectomy and re-formation of the anterior chamber. In glaucomatous eyes with open angles, trabeculecomy was performed if there was poor response to topical anti-glaucoma medications.

Surgery for congenital pediatric cataract increases the risk for developing aphakic glaucoma. Preoperative angle findings do not suggest a role in pathogenesis of this form of glaucoma ${ }^{12}$.

The precise cause for the open angle glaucoma following pediatric cataract surgery is not known but may be triggered by trabecular meshwork dysfunction from surgically induced inflammation, corticosteroids induced increased IOP, damage to the developing angle structures by the residual lens fibers or vitreous 
interfering with the aqueous drainage or angle maldevelopment ${ }^{13}$.

Two risk factors most commonly associated with glaucoma after pediatric cataract surgery include age at the time of surgery and micro-cornea. There is a higher risk in infants operated during the first year of life. A number of studies ${ }^{14,15}$ report an increased risk of glaucoma at different ages in the first 12 months of life. Some observers ${ }^{16}$ have reported that cataract surgery in the first 9 months of age carries a higher risk of aphakic glaucoma.

In this series, we operated on 110 infants (220 eyes) having bilateral congenital cataracts with ages ranging from 2 months to 30 months. Both eyes were operated in the same sitting. Based on eye count, 12 eyes $(5.45 \%)$ of our patients developed aphakic glaucoma. Based on the patients count 7 of our patients $(6.36 \%)$ developed aphakic glaucoma. Postoperative glaucoma following pediatric cataract surgery has been reported to vary between $6 \%$ and $26 \%$ of eyes ( $15 \%$ to $45 \%$ of patients) among children operated before, as well as after one year of age ${ }^{17,18}$.

Rabiah ${ }^{19}$ has reported an incidence of $37 \%$ if the cataract was removed during the first 9 months of age. The risk dropped to $14 \%$ when surgery was delayed to between 9 months and 2 years of age. The risk of developing glaucoma further drops to only $9 \%$ if surgery is performed between 2 and 3 years of age. After bilateral lensectomy within the first month of life, Vishwanath et $\mathrm{al}^{8}$ found an incidence of $50 \%$ in at least one eye which decreased to $14.9 \%$ if surgery was delayed beyond one year. The incidence of glaucoma in our patients is relatively lower compared to the above studies.

We need to counsel the parents, and relatives about the importance of regular examination and follow-up. It will be worthwhile to involve both parents during the course of the treatment of their child, from identification to surgery and follow-ups. The pediatric unit should have trained staff with childfriendly attitude for greater acceptance of the available pediatric ophthalmology services.

Aphakic glaucoma itself poses a significant diagnostic challenge, as classical manifestations are not always present and children are uncooperative for proper examination. It can be extremely challenging to measure the IOP with the child awake and sedation is usually required. In our series we did not see any patient before 2 months of age because of late presentation.
Fortyseven infants (42.72\%) were operated between 2 months and 6 months of age. Sixty three patients $(57.26 \%)$ were operated between 7 months and 30 months. We did not perform posterior capsulotomy and anterior vitrectomy in any of our patients. This could be the reason for the lower incidence of glaucoma in our patients.

Michaelides and co workers ${ }^{17}$ have reported a marked increase in risk of aphakic glaucoma after bilateral lensectomies at an early age. They have also observed that respecting the posterior capsule may be associated with a lower rate of aphakic glaucoma.

The pattern of aphakic glaucoma in our series was bimodal as reported by Mills et $\mathrm{al}^{2}$. In our series 4, $(3.63 \%)$ of our patients developed early-onset glaucoma. Two patients developed bilateral whereas two patients developed unilateral pupil block/angle closure glaucoma. The time interval between cataract extraction and development of pupillary block was from 19 days to 67 days' post operative. In our study, pupil block with secondary angle closure caused the early-onset post-operative aphakic glaucoma. This was due to severe inflammation leading to synechia formation, absence of peripheral iridectomy, and poor pupillary dilatation causing pupil block and raised IOP.

Early-onset glaucoma typically occurs during the first few weeks after surgery and has an abrupt onset. Mills and co-workers ${ }^{2}$ have reported the occurrence of pupillary block glaucoma within the first few months after lensectomy while the open-angle glaucoma type has a delayed onset (average 7.4 years). Chen et al 16 however, have not witnessed the bimodal pattern in their patients operated for congenital cataracts. They found the filtration angles open in $94 \%$ of their patients. In our series, eyes developing glaucoma in the first few weeks after surgery had closed angles.

The open-angle glaucoma occurring in both eyes in three of our patients was delayed for a period from 3 months to 6 years. Patients with delayed onset glaucoma (6 eyes) in our series were without any symptoms and were diagnosed on routine examination.

In a study conducted by Simon et al ${ }^{4}$ open angle glaucoma occurred 5.5 years after surgery in children. In other studies ${ }^{1}$, the onset of glaucoma was delayed up to 12.2 years following cataract surgery in the pediatric age group. In our follow up of 3 years to 14 years, we found a delay of 3 months to 6 years before the patients developed open angle glaucoma. The 
incidence of open angle glaucoma increases with longer post operative follow up of these patients. Children operated for congenital cataracts have a perpetual risk of developing open angle glaucoma throughout their lives $18,19,20$.

Whether an intact posterior capsule and putting an intraocular lens (IOL) has a protective role for development of aphakic glaucoma is not clear. Although primary posterior capsulectomy and anterior vitrectomy may aid in early visual recovery, and may help reduce the risk pupil block but it also increases the chances of open-angle glaucoma down the line. Michel Michaelides et $\mathrm{al}^{17}$ found the development of aphakic glaucoma in $100 \%$ of their patients who had posterior capsulotomy during lensectomy for pediatric cataracts.

Rabiah $^{21}$ also has reported an increased risk of aphakic glaucoma after primary posterior capsulotomy/anterior vitrectomy. Papadopoulos et $\mathrm{al}^{22}$ noted a reduced incidence of aphakic glaucoma when the posterior capsulotomy was not performed at the time of primary lens aspiration in children. In a series of 377 eyes who had lensectomy with posterior chamber IOLs, Asrani et al found only one patient developing glaucoma. The follow up however, was only 3.9 years.

The limitation of our study was that it was performed at a single center. Further studies are needed with more patients to determine more generalizable results. The challenges we are facing include; lack of awareness about pediatric cataracts, delay in presentation for surgery, poor access to quality surgical care, and poor follow-ups. In addition, lack of financial resources, inadequate health facilities, and an insufficient number of pediatric ophthalmologists are other major obstacles.

\section{CONCLUSION}

Pediatric aphakic glaucoma may be angle-closure type secondary to pupillary block ${ }^{2}$ which occurs within the first few weeks after surgery. Etiology of this type of glaucoma include surgery at an early age, severe inflammatory reaction, poor pupil dilatation, not performing an iridectomy and shallow anterior chamber due to poor wound suturing.

Post operative open angle glaucoma is unpredictable and can occur months and even years after surgery. ${ }^{1}$ This form of glaucoma is probably not directly related to the procedure itself and often difficult to manage.

\section{REFERENCES}

1. Asrani SG, Wilensky JT. Glaucoma after congenital cataract surgery. Ophthalmology, 1995; 102: 863-867.

2. Mills MD, Robb RM. Glaucoma following childhood cataract surgery. J Pediatric Ophthalmology \& Strabismus, 1994; 31: 355-360.

3. Russell-Eggitt I, Zamiri P. Review of aphakic glaucoma after surgery for congenital cataract. J Cataract Refract Surg. 1997; 22: 664-668.

4. Simon JW, Mehta N, Simmons ST, Catalano RA, Lininger LL. Glaucoma after paediatric lensectomy / vitrectomy. Ophthalmology, 1991; 98: 670-674.

5. Walton DS. Pediatric aphakic glaucoma: A study of 65 patients. Trans Am Ophthalmol Soc. 1995; 93: 403-420.

6. Gelbart SS, Hoyt CS, Jastrebski G, Marg E. Long-term visual results in bilateral congenital cataracts. Am J Ophthalmol. 1982; 93: 615-21.

7. Gregg FM, Parks MM. Stereopsis after congenital monocular cataract extraction. Am J Ophthalmol.

8. Vishwanath $\mathbf{M}$, Cheong-Leen R, Taylor D, RusselEggit I, Rahi J. Is early surgery for congenital cataract a risk factor for glaucoma? Br J Opthalmol. 2004; 88: 905910.

9. Johnson CP, Keech RV. Prevalence of glaucoma after surgery for PHPV and infantile cataracts. J Pediatr Ophthalmo Strabismus. 1996; 33 (1): 14-7.

10. Beck A, Chen T, Freedman S. Definition, classification, differential diagnosis. In Weinreb R, Grajwski A, Papadopoulos A, Grigg J, Freedman S, editors. Childhood Glaucoma: World Glaucoma Association, consensus series -9. Amersterdam, The Netherland: Kugler Publications; Ch. 1, p 3.

11. Cecilia Fenerty, Nicola Freeman, John Grigg. Glaucoma following cataract surgery. In Weinreb. R, Grajewski A, Papadopoulos A, Grigg J, Freedman S. editors. Childhood Glaucoma: World Glaucoma Association, Consensus series 9, Amersterdam, The Netherland: Kugler Publications; 2013. Ch. 10: p. 233248.

12. Lambert SR, Lynn M, Drews-Botsch C, Loupe D, Plager DA, Medow NB, et al. A comparison of grating visual acuity, strabismus and reoperation outcomes among children with aphakia and pseudophakia after unilateral cataract surgery during the first 6 months of life. J AAPOS. 2001; 5 (2): 70-5.

13. Haargaard B, Ritz C, Oudin A, Wohlfahrt J, Thygesen J, Oslen T. et al. Risk of glaucoma after pediatric cataract surgery. Invest Ophthalmol vis Sci. 2008; 49 (5): 1791-6.

14. Phelps CD, Arafat NI. Open-angle glaucoma following surgery for congenital cataracts. Arch Ophthalmol. 1977; 95: 1985-7.

15. Pressman SH, Crouch ER Jr. Pediatric aphakic glaucoma. Ann Ophthalmol. 1983; 15: 568-73.

16. Chen TC, Walton DS, Bhatia LS. Aphakic glaucoma after congenital cataract surgery. Arch Ophthalmol. 2004; 122: 1819-1825. 
17. Michaelides M, Bunce C, Adams GG. Glaucoma following congenital cataract surgery - the role of early surgery and posterior capsulotomy. BMC Ophthalmology, 2007; 7: 13.

18. Freedman SF, Lynn MJ, Beck AD, Bothun ED, Örge FH, Lambert SR; Infant Aphakia Treatment Study Group. Glaucoma-Related Adverse Events in the First 5 Years After Unilateral Cataract Removal in the Infant Aphakia Treatment Study. JAMA Ophthalmol. 2015 Aug;133(8):907-14.

19. Zhang S, Wang J, Li Y, Liu Y, He L, Xia X. The role of primary intraocular lens implantation in the risk of secondary glaucoma following congenital cataract

\section{Author's Affiliation}

Zia Muhammad

MBBS, MCPS, FCPS, FICS, Fellowship in Pediatric Ophthalmology, University of Sydney, Australia.

Prof \& Head Department of Ophthalmology,

Bacha Khan Medical College,

Mardan, Pakistan.

John Grigg

MBBS (QLD) MD (SYD) FRANZCO FRACS

Professor and Head, Discipline of Ophthalmology, Save Sight Institute, Sydney Eye Hospital Campus Sydney Medical School, the University of Sydney,

Ikramullah

MBBS, M.Phil (Community Medicine)

Prof. and Head, Department of Community Medicine, Nowshera Medical College, Nowshera. surgery: A systematic review and meta-analysis. PLoS One. 2019 Apr 1;14(4):e0214684.

20. Chen D, Gong XH, Xie H, Zhu XN, Li J, Zhao YE. The long-term anterior segment configuration after pediatric cataract surgery and the association with secondary glaucoma. Sci Rep. 2017 Feb 21;7:43015.

21. Rabiah P. Frequency and predictors of glaucoma after pediatric cataract surgery. Am J Ophthalmol. 2004; 137: 30-37.

22. Papadopoulos M, Khaw PT. Meeting the challenge of glaucoma after paediatric cataract surgery. Editorial, Eye, 2003; 17: 1-2.

Ihsan Ali

MBBS. Trainee Medical Officer, Department of Ophthalmology, Mardan Medical Complex, Mardan.

\section{Author's Contribution}

Zia Muhammad

Data collection, Manuscript writing, Critical analysis.

John Grigg

Manuscript review, critical analysis.

Ikramullah

Data analysis, manuscript writing.

Ihsan Ali

Data analysis, manuscript writing. 